\title{
Determination of Landslide Zone Vulnerability Based on Soil Property at Puncak Area, Cisarua District, Bogor Regency, West Java Province
}

\author{
Eva Grace* ${ }^{1}$, Sofyan Rachman ${ }^{2}$, Harry Pramudito ${ }^{3}$ \\ ${ }^{1}$ Geological Engineering Department, Faculty of Earth and Energy Technology, Trisakti University, Box.11450. Jakarta. Indonesia \\ ${ }^{2}$ Geological Engineering Department, Faculty of Earth and Energy Technology, Trisakti University, Box.11450. Jakarta. Indonesia \\ ${ }^{3}$ Geological Engineering Department, Faculty of Earth and Energy Technology, Trisakti University, Box.11450. Jakarta. Indonesia
}

Correspondence Author: Eva Grace, Geological Engineering Department, Faculty of Earth and Energy Technology, Trisakti University, Box.11450. Jakarta. Indonesia

E-mail: evagracesimbolon@yahoo.co.id

Received date: 22 April 2019, Accepted date: 22 July 2019, Online date: 25 August 2019

Copyright: @ 2019 Eva Grace, Sofyan Rachman, Harry Pramudito.2019. This is an open-access article distributed under the terms of the Creative Commons Attribution License, which permits unrestricted use, distribution, and reproduction in any medium, provided the original author and source are credited.

\begin{abstract}
Analysis to know the values of liquid limit, plastic limit, permeability, and direct shear, physical and mechanics properties in research area in their ability to handle any loads and force on them, so, by soil bearing capacity values and those aspects can be known safe zone, middle zone, hazard zone. Then, in landslide areas zonation through soil bearing capacity values in research area, gets constituent rocks with different weathering which is obtained from residual soil, that will be analyzed, they are, plastic limit, permeability, physical and mechanics properties, and direct shear to know soil bearing capacity values. So, based on that analysis with highest soil bearing capacity value 346,9086 ton/m2 and lowest value is 8,353747 ton $/ \mathrm{m} 2$
\end{abstract}

Keywords: Geological Engineering, Physical and mechanical properties, Landslide, Soil Bearing Capacity, Liquid Limit, Plastic Limit, Permeability

\section{INTRODUCTION}

Landslides are geological disasters that occur due to the movement of surface constituent material in the form of soil or rock, which is affected by several dominant factors, namely hydrology, physical properties of soil or rock, topography, climate, and load above it. Therefore, it is necessary to research the carrying capacity of soil or rock to minimize the potential of land slides.

The carrying capacity of the soil or rock is the ability of the soil or rock itself to receive loads that work around it. Soil or rock carrying capacity in engineering geology to determine the value obtained by rocks when given absolute pressure from measurements and laboratory tests. Thus, it can be applied to the types and stages of construction that correspond to these values.

\section{BASIC THEORY}

\subsection{Landslide}

Landslides are one of the harmful soil movements. Landslides occur due to various aspects such as high rainfall, relatively large slope, and the power of the dukug itself in response to the overload which exceeds the carrying capacity

\subsection{Soil Bearing Capacity}

Soil bearing capacity is the ability of the soil to support the load, both in the form of its foundation load and other loads, namely in the type of a fixed load, moving load, wind load and earthquake load [15]. So that in its application for landslides, how and how much the bearing capacity of the soil in an area and if the loads passing the soil bearing capacity can provide a large with enough potential ground movement.

\section{RESEARCH METHODOLOGY}


There is a research method that is conducted to achieve the data and analysis to be obtained in this research area, as follows:

\section{Preparation and Planning Stage}

At this stage, preparations were made in the form of proposals, permits to the government, collecting literature related to the topics to be discussed, named regional geological maps, topographic maps (National Geospatial Information Network) and geological information of the research area and surrounding areas by previous researchers, A survey of research areas was conducted to determine the condition of the current research area and information that could be obtained at the time of the study. Planning the next research phase.

\section{Data retrieval}

In this research, there are two kinds of data which is used to complete the research analyze. The first one is the primary.data which is consist of 4 laboratory tests. Then the second one is secondary data obtained from previous data has done by previous researchers, consist of two kinds of data. Those dates, primary and secondary data will be used for final result, map of disaster vulnerability zoning in research area.

\section{Primary data}

Primary data obtained through geological mapping, technical geology mapping and laboratory testing were carried out on 8 hand drill samples in the research area, which is called liquid limit test, plastic limit test, permeability test, direct shear test, soil physical properties test.

- $\quad$ Physical Properties of Soil (ASTM D6473-15).

- $\quad$ Plastic Limit (SNI 1966: 2008).

- $\quad$ Soil Permeability (SNI 2435: 2008).

- $\quad$ Direct Shear (SNI 2813: 2008)

\section{Secondary data}

Secondary data used as data that will be analyzed which is land use data (Google Earth, 2018) to know some information about landuse above research area, and rainfall data in the study area, it shows rainfall intensity in research area based on Rainfall Map (Monthly Rainfall Data Period 1970 - 2000, BMKG) of 3751 - 4000 mm3.

\section{RESULT AND DISCUSSIONS}

By the eight sample from eight locations (Figure 1) will be getting values by laboratory tests, they are plastic limit test value, permeability tests, soil physical properties test (Table 1) and direct shear test to obtain values (Table 2), (Table 3), (Table 4), (Table 5), (Table 6), (Table 6), (Table 7), (Table 8), (Table 9), which is needed to determine the value of soil bearing capacity in the area (based on Grace's Thesis, 2018).

Table 1 Table of sample measurement results through Physical Properties Laboratory Test (Grace, 2018).

\begin{tabular}{|c|c|}
\hline No. Sample & Natural Density $(\mathrm{gr} / \mathrm{cc})$ \\
\hline 1 & 0,471128021 \\
\hline 2 & 0,470673635 \\
\hline 3 & 0,33476112 \\
\hline 4 & 0,318698817 \\
\hline 5 & 0,440098806 \\
\hline 6 & 0,463157895 \\
\hline 8 & 0,439575488 \\
\hline
\end{tabular}

In sample 1 there were three laboratory tests (Direct Hear). Plastic limit material, soil permeability laboratory test, and direct shear laboratory test to get cohesion and phi values/.

Table 2: Results of laboratory test measurements in sample 1 (Grace, 2018).

\begin{tabular}{|c|c|c|}
\hline Sample & 1 & Weighting \\
\hline Koef. Permeability (cm/s) & 0,94 & 1 \\
\hline Phi $\left({ }^{\circ}\right)$ & 18,41 & \\
\hline Kohesi (kPa) & 0,5309 & \\
\hline Plasticity (\%) & 56,45 & 1 \\
\hline
\end{tabular}


Like sample 1, three similar laboratory tests were carried out, the results of measurements were as follows

Table 3: Results of measurement of laboratory tests on sample 2 (Grace, 2018).

\begin{tabular}{|c|c|c|}
\hline Sample & 2 & Weighting \\
\hline Koef. Permeability $(\mathrm{cm} / \mathrm{s})$ & 1,83 & 1 \\
\hline Phi $\left(^{(}\right)$ & 28,16 & \\
\hline Kohesi (kPa) & 0,1325 & \\
\hline Plasticity $(\%)$ & 36,83 & 2 \\
\hline
\end{tabular}

Then also sample 2 was carried out the three similar laboratory tests, like previous samples, and also for the next samples.

Table 4: Results of laboratory test measurements in sample 3 (Grace, 2018).

\begin{tabular}{|c|c|c|}
\hline Sample & 3 & Weighting \\
\hline Koef. Permeability (cm/s) & 1,36 & 1 \\
\hline Phi ( ${ }^{(9)}$ & 23,27 & \\
\hline Kohesi (kPa) & 0,2004 & \\
\hline Plasticity (\%) & 54,51 & 1 \\
\hline
\end{tabular}

Table 5: Result of Laboratory test measurements in sample 4 (Grace, 2018).

\begin{tabular}{|c|c|c|}
\hline Sample & 4 & Weighting \\
\hline Koef. Permeability (cm/s) & 3,16 & 3 \\
\hline Phi ( $\left.{ }^{9}\right)$ & 29,72 & \\
\hline Kohesi (kPa) & 0,059 & \\
\hline Plasticity (\%) & 21,55 & 2 \\
\hline
\end{tabular}

Table 6: Result of Laboratory test measurements in sample 5 (Grace, 2018).

\begin{tabular}{|c|c|c|}
\hline Sample & 5 & Weighting \\
\hline Koef. Permeability (cm/s) & 3,27 & 1 \\
\hline Phi (") & 36,45 & \\
\hline Kohesi (kPa) & 0,0156 & \\
\hline Plasticity (\%) & 10,31 & 3 \\
\hline
\end{tabular}

Table 7: Result of Laboratory test measurements in sample 6 (Grace, 2018).

\begin{tabular}{|c|c|c|}
\hline Sample & 6 & Weighting \\
\hline Koef. Permeability (cm/s) & 7,77 & 1 \\
\hline Phi $\left({ }^{\circ}\right)$ & 45,75 & \\
\hline Kohesi (kPa) & 0,4184 & \\
\hline Plasticity (\%) & 55,06 & 1 \\
\hline
\end{tabular}

Table 8: Result of Laboratory test measurements in sample 7 (Skripsi Grace, 2018).

\begin{tabular}{|c|c|c|}
\hline Sample & 7 & Weighting \\
\hline Koef. Permeability (cm/s) & 15,58 & 3 \\
\hline Phi ( ${ }^{(2)}$ & 21,04 & \\
\hline Kohesi (kPa) & 0,2712 & \\
\hline Plasticity (\%) & 57,41 & 1 \\
\hline
\end{tabular}

The last sample is sample 9 , which is the values came from calculation and measurement of three similar laboratory test just like previous samples; they are the plastic limit — direct shear and permeability laboratory tests.

By those laboratory tests, all data will be analyzed to get the combination of all laboratory tests and next will combine with another data, two secondary data, they are rainfall intensity data, and land of used data. 
Table 9. Result of Laboratory test measurements in sample 8 (Skripsi Grace, 2018).

\begin{tabular}{|c|c|c|}
\hline Sample & 8 & Weighting \\
\hline Koef. Permeability (cm/s) & 32,71 & 5 \\
\hline Phi ( ${ }^{(2)}$ & 27,9 & \\
\hline Kohesi (kPa) & 0,1861 & \\
\hline Plasticity (\%) & 23,49 & 2 \\
\hline
\end{tabular}

Through the results of measurements of laboratory direct shear tests, it will show the values of cohesion and shear angle which is applied in the calculation of soil bearing capacity (Table 10) with the formulas (Terzaghi, 1993):

qult $=$ C.Nc+yb.Nq.Df+0,5.yb.B.Ny

Where,

qult $=$ carrying capacity of the ultimate land

$\mathrm{c}=$ cohesion

$\mathrm{Nc}, \mathrm{Nq}, \mathrm{Ny}=$ Terzaghi Carrying Factor is determined by the magnitude of the inner shear angle

$\mathrm{yb}=$ weight of soil volume

Df $=$ Depth of Foundation Base

$\mathrm{B}=$ The foundation width is considered 1.00 meters

Then to find the Soil Bearing capacity of the land permit, the formula is used.

\section{$\mathbf{q}=\mathbf{q u l t} / \mathbf{S f}$}

Where,

$\mathrm{q}=$ the value of the carrying capacity of the land permit

quit $=$ value of ultimate bearing power

$\mathrm{Sf}=$ security factor (considered 3 )

So, by this calculation of soil bearing capacity, values that will be used to make a soil bearing capacity is soil bearing capacity of the land permit, that obtained from the multiplication of three of soil bearing capacity pure values.

Table 10: Results of measurements of laboratory tests for soil carrying capacity in all eight samples (Eva Grace's Thesis, 2018).

\begin{tabular}{|c|c|}
\hline No Sample & Soil Bearing Capacity (ton/m2) \\
\hline 1 & 42,16816 \\
\hline 2 & 170,7934 \\
\hline 3 & 99,84771 \\
\hline 4 & 346,9086 \\
\hline 5 & 8,353747 \\
\hline 6 & 17,97856 \\
\hline 7 & 214,6679 \\
\hline 8 & 198,8033 \\
\hline
\end{tabular}

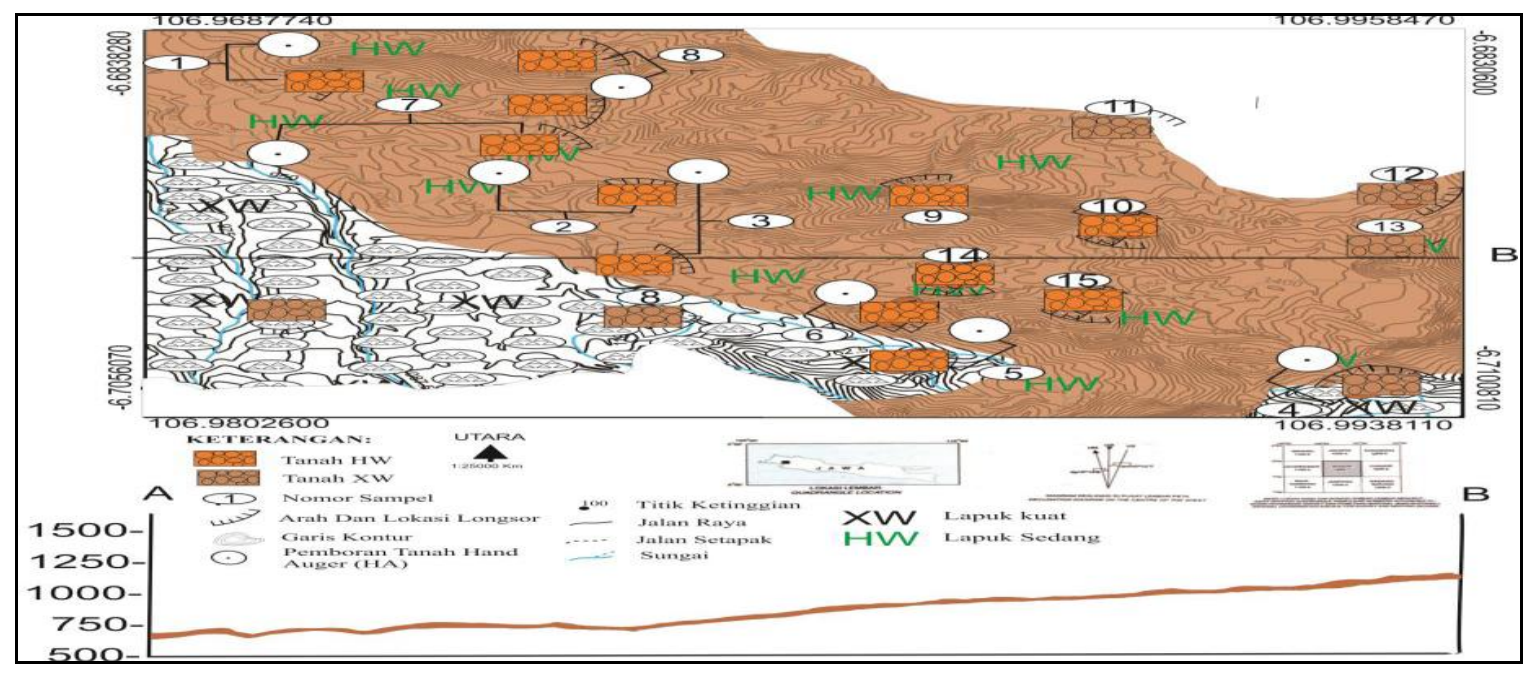

Figure 1. Map of observation locations and landslides in the study area (Eva Grace, 2018). 
By those sampling locations, the spreading of Plastic limit values (Figure 2), Soil permeability values (Figure 3), and Soil bearing capacity values (Figure 4) that will be overlayed with two secondary data , they are Rainfall intensity (Monthly Rainfall Data Period 1970 - 2000, BMKG) (Figure 5) and Land of used (Google Earth, 2018) (Figure 6). The plastic limit map is come from plastic limit values, then using classification of plastic limit classification by Anas Luthfi and Tigor Tobing (1995) that will be classification them into seven zones, but in research area only classification into two zones

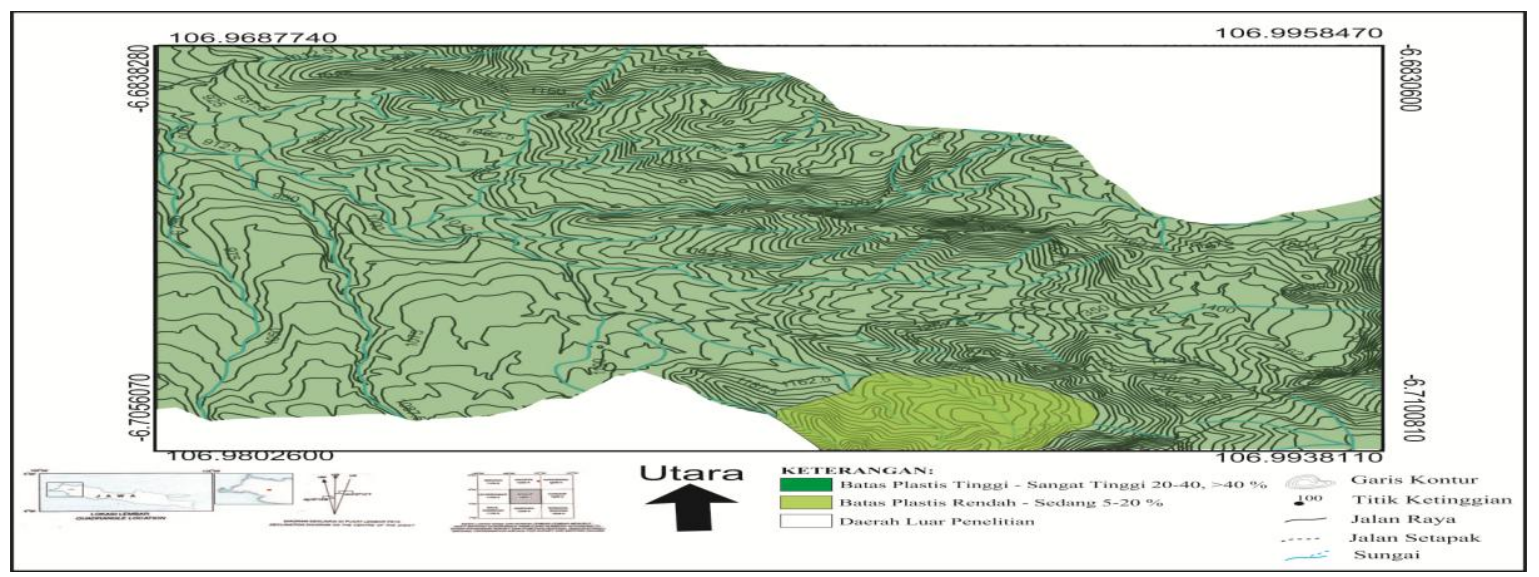

Figure 2. Map of Plastic limit in the study area (Eva Grace, 2018).

Soil permeability zoning map is obtained from soil permeability values than using classification of soil permeability by Anas Luthfi and Tigor Tobing (1995) that will be classification them into five zones, but in research area only classified into one zone.

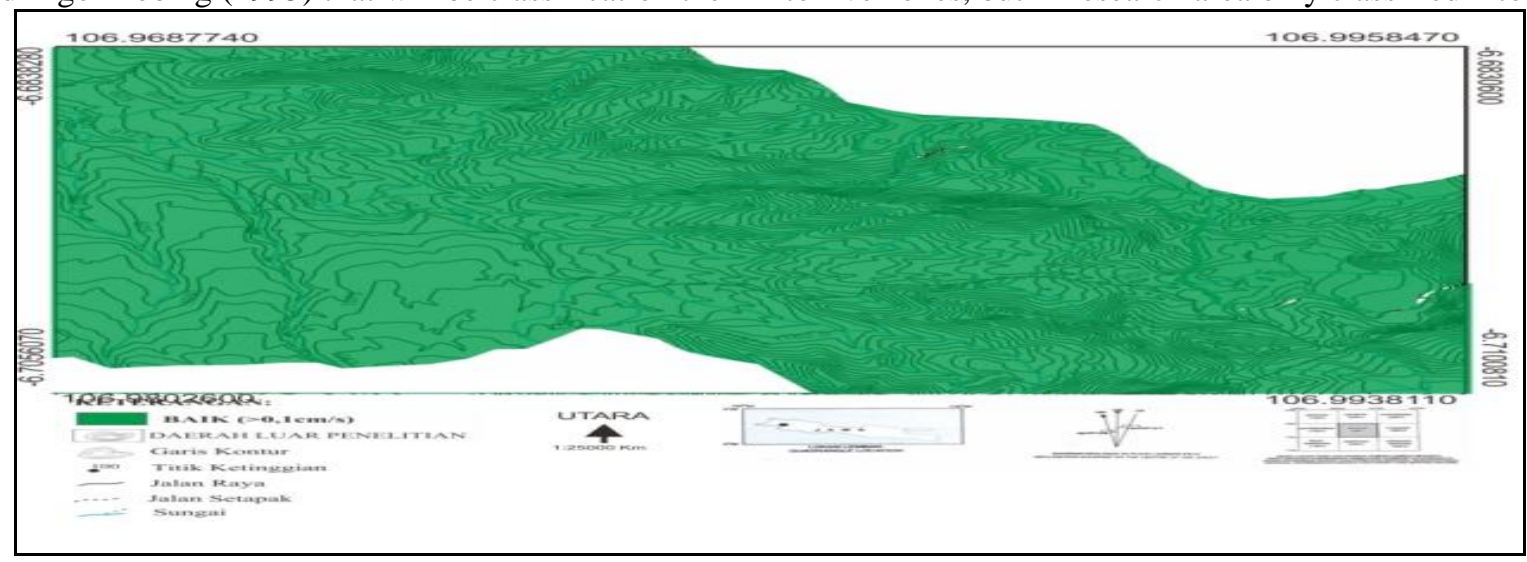

Figure 3. Map of Permeability in the study area (Eva Grace, 2018)

Soil bearing capacity map is obtained from soil bearing capacity values then classified by soil bearing capacity classification from Anas Luthfi and Tigor Tobing (1995) in three classifications, but in this area only covers two classifications.

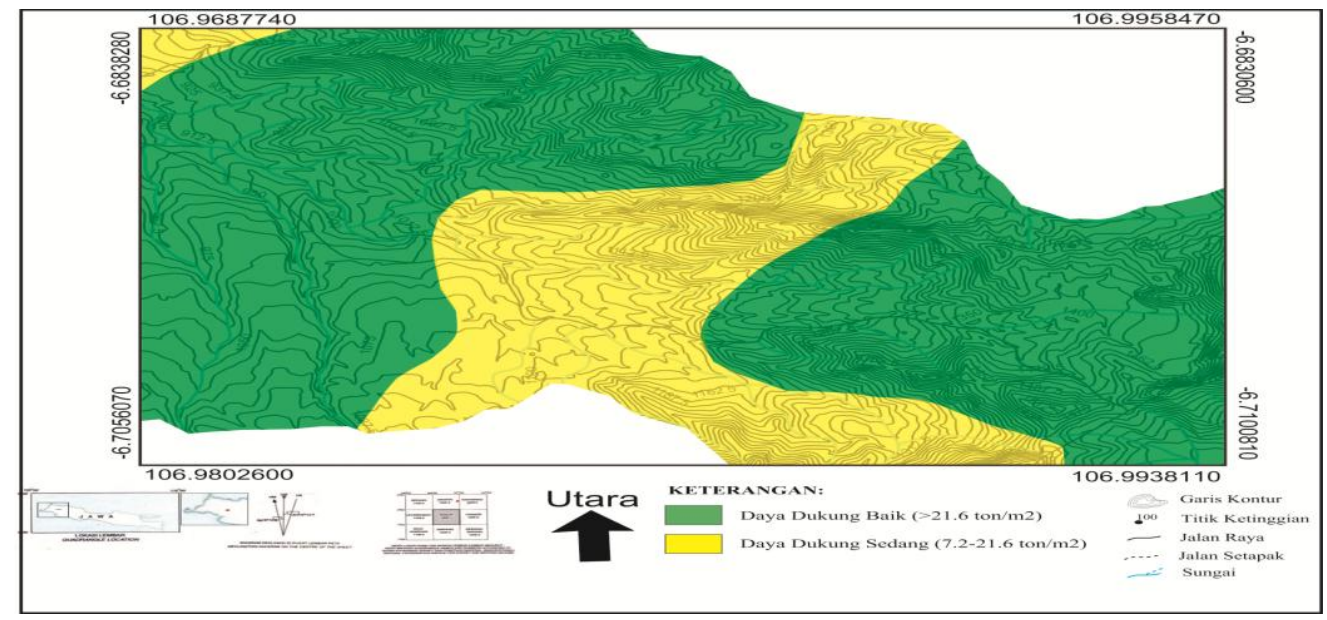

Figure 4 Map of Soil bearing capacity in the study area (Eva Gra1ce, 2018) 
For rainfall intensity mP, the data obtained from. Rainfall Map (Monthly Rainfall Data Period 1970 - 2000, BMKG) of 3751 $4000 \mathrm{~mm} 3)$, that classification research area to be a zone with similar rainfall intensity.

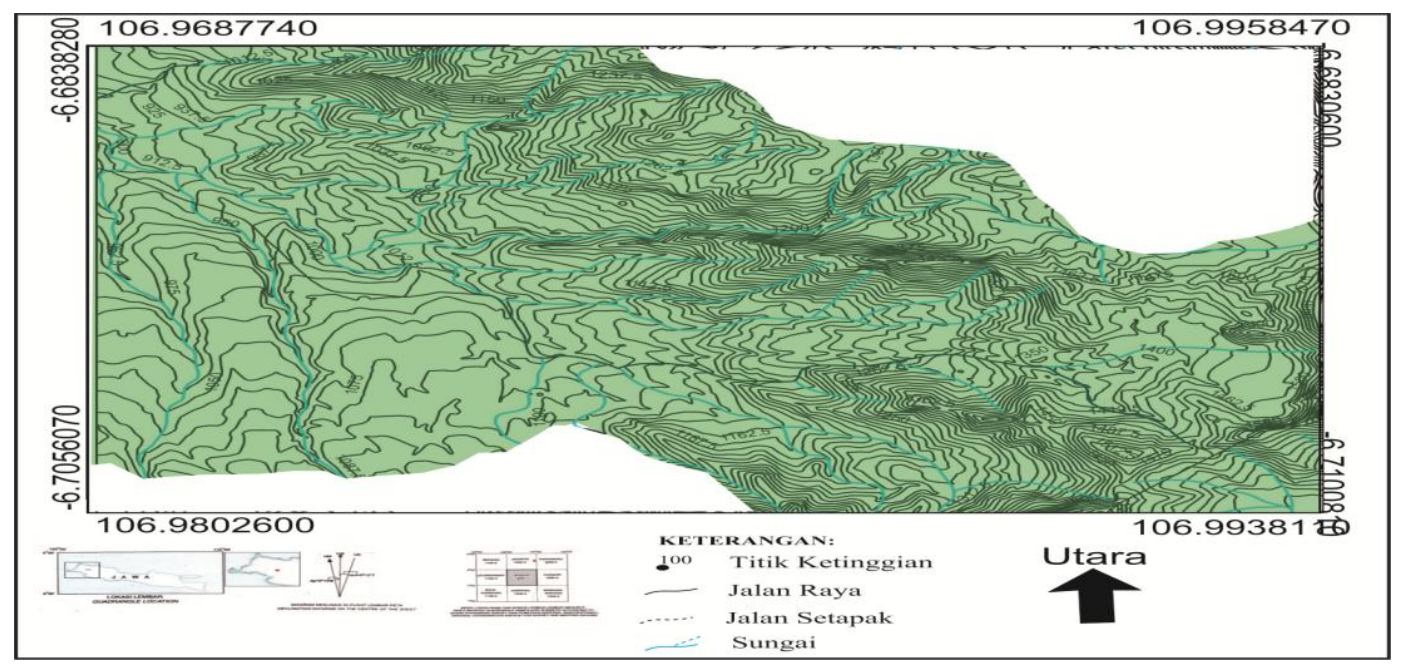

Figure 5 Map of Rainfall intensity in the study area (Monthly Rainfall Data Period 1970 - 2000, BMKG)

Then the land of the used map is obtained from secondary data which is Google Earth (2018), to get information about land of used that covers in this research area, nowadays.

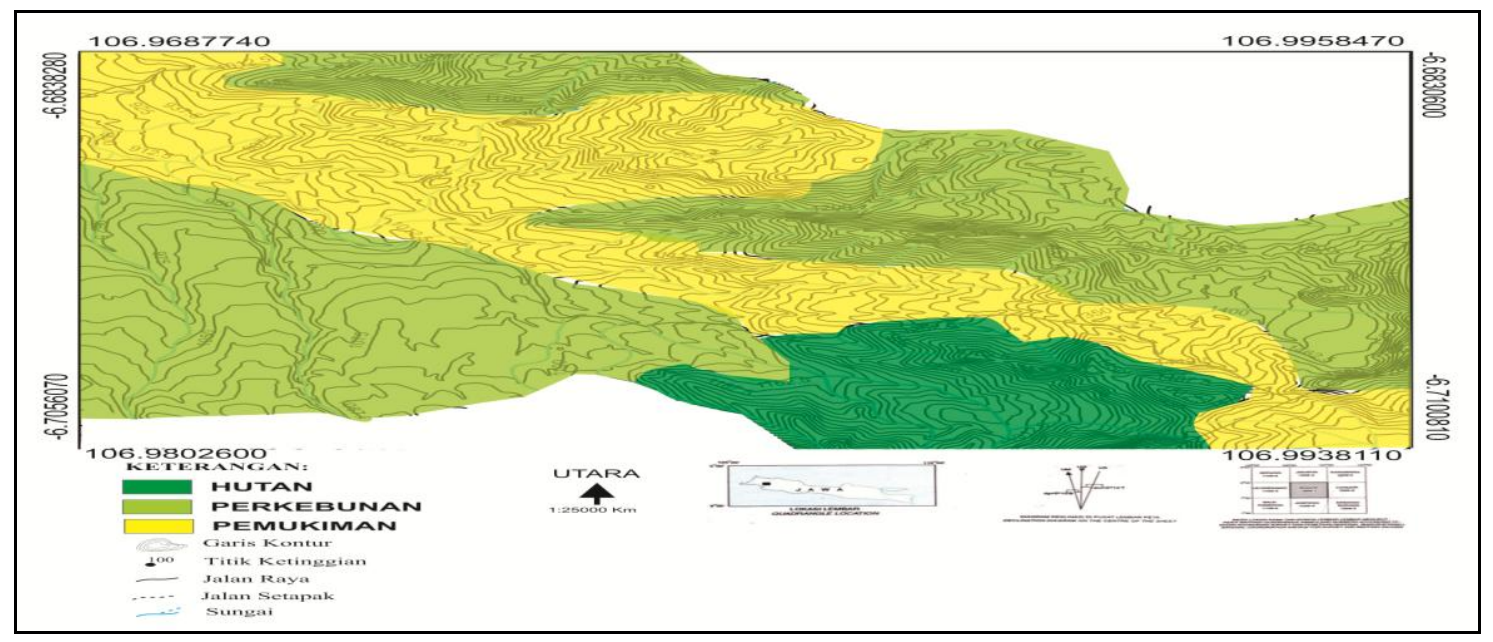

Figure 6 Map of Land of used in the study area (Eva Grace, 2018)

Then based on plastic limit laboratory tests, permeability, direct shear, physical properties of the soil, through the bearing capacity of the soil, and overlayed with rainfall intensity map and land of a used map, a map of landslide vulnerability is obtained (Figure 7). 


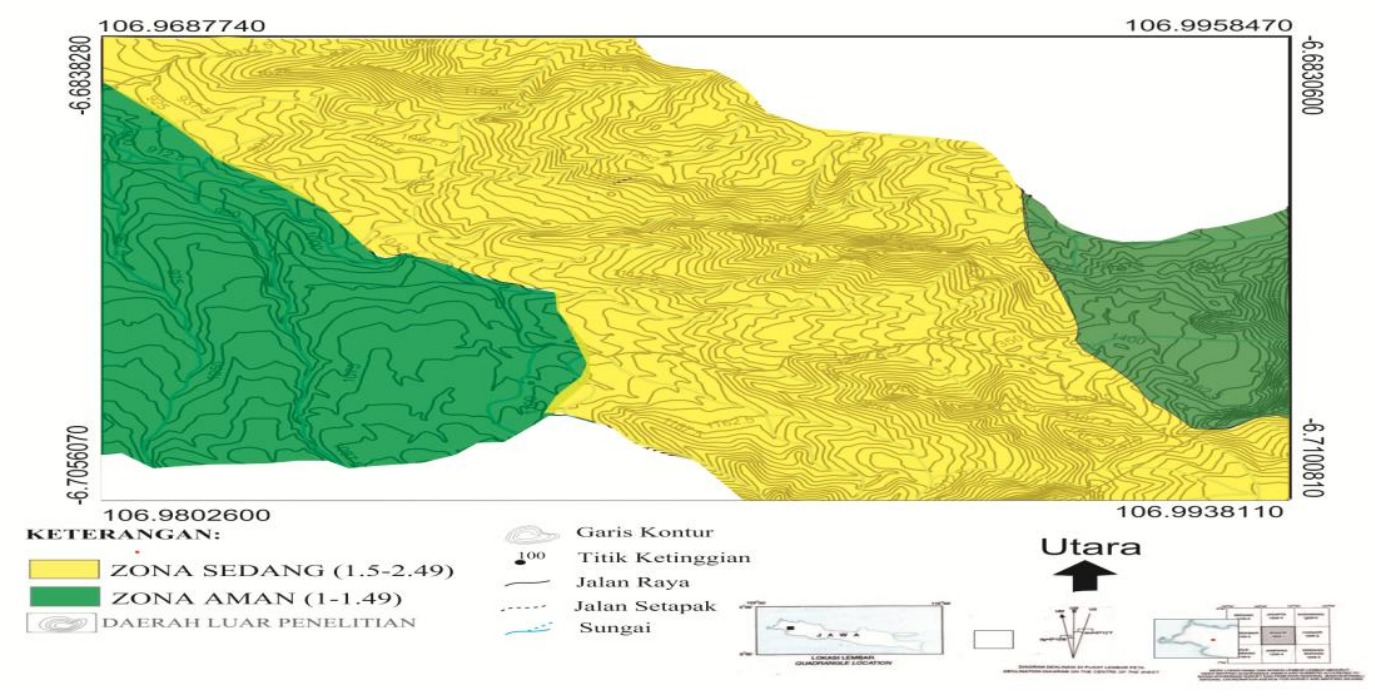

Figure 7. Map of disaster vulnerability zoning in the study area (Grace, 2018).

This zonation of landslide vulnerability map will show information of landslide potential in research area only by Plastic limit data, permeability data, direct shear data, rainfall intensity data, and land of used data. All data beyond this analysis might be changing zonation of landslide vulnerability map in another analysis. Zonation of landslide vulnerability map might be changing, following the conditions of that area. By those data, research area obtained from one lithology, it is Breccia (Andesite), and there are three units of engineering, the Perfectly Weathered Stone Unit, the Perfect Laput Rock Unit, and the Good Weathered Stone Unit.

\section{CONCLUSIONS}

The conclusions obtained from the analysis in the study area are:

- $\quad$ Research area obtained from one lithology, Breccia (Fragments: Andesite).

- Geologically, there are three units of engineering, the Perfectly Weathered Stone Unit, the Perfect Laput Rock Unit, and the Good Weathered Stone Unit.

- There is only using three laboratory tests to analyze research area, they are, direct shear test, plastic limit test, and permeability test.

- Secondary data that actually used for this analysis are rainfall intensity data and land of use data.

- Based on the combination of Plastic Limit, Permeability, Rainfall and Soil Carrying Capacity Map, based on the analysis, the research area divided into two zones, the safe zone is green, and the medium zone is yellow.

\section{BIBLIOGRAPHY}

[1] ASTM D 6473. Standard Test Method For physical Test.

[2] BMKG., 2003, Annual Rainfall Data Period 1971-2000.

[3] Effendi A, C, Kusnanda and Hermanto B, 1998, Bogor Sheet Geology Map, Answerarat, 1: 100,000 Scale, Geological Research and Development Center, Bandung

[4] Grace, Eva. 2018. Zoning of Regions Prone to Landslides Through Analysis of the Carrying Capacity of the Peak Areas, Cisarua District, Bogor Regency, West Java. Essay. Trisakti University. Jakarta.

[5] Google Earth (2018): Location of Research Area. https://earth.google.com on April 13, 2018

[6] Indonesia Geospatial Portal (2018): Topographic Map Scale 1: 50000 Research Area,

[7] https://tanahair.indonesia.go.id/portal-web on April 7, 2018.

[8] International Society Rock Mechanics., 1978 Clasifications of Weathering level

[9] Geological Survey Center, 2013, Journal of Geological Resources

[10] Sudjatmiko, 1972, Cianjur Sheet Geological Map, Answerarat, 1: 100,000 Scale, Geological Research and Development Center, Bandung

[11] SNI 1966: 2008. Plastic Limit Testing Method

[12] SNI 1967: 2008. Liquid Limit Testing Method

[13] SNI 2435: 2008. Soil Permeability Testing Method

[14] SNI 2813: 2008. Direct Shear Testing Method

[15] Terzaghi, Karl, Peck, B., Ralph. Soil Mechanics in the Practice of Volume Engineering -1. Erlangga Publishers, Jakarta, 1993.

[16] Tubing Tigor and Anas Luthfi. 1995., Bogor Sheet Geological Engineering Map 